\title{
Auctions: Research Opportunities in Marketing ${ }^{1}$
}

DIPANKAR CHAKRAVARTI

University of Colorado, Boulder

Corresponding author: Leeds School of Business, University of Colorado, Boulder, CO 80309-0419;

Tel. (303) 492-1311; Fax: (303) 492-5962; e-mail: Dipankar.Chakravarti@Colorado.edu

ERIC GREENLEAF

New York University

ATANU SINHA

University of Colorado, Boulder

AMAR CHEEMA

University of Colorado, Boulder

JAMES C. COX

University of Arizona

DANIEL FRIEDMAN

University of California, Santa Cruz

TECK H. HO

University of Pennsylvania

R. MARK ISAAC

University of Arizona

ANDREW A. MITCHELL

University of Toronto

AMNON RAPOPORT

University of Arizona

MICHAEL H. ROTHKOPF

Rutgers University

JOYDEEP SRIVASTAVA

University of California, Berkeley

RAMI ZWICK

Hong Kong University of Science and Technology

Accepted February 2002

${ }^{1}$ This paper is based on session proceedings at the UC-Berkeley 2001 Choice Symposium held at the Asilomar Conference Center, June 1-5, 2001. 


\begin{abstract}
Despite growing interest in traditional and Internet auctions, the marketing literature on auctions is sparse. This paper outlines selected aspects of the research opportunity. We provide a brief description of the major auction mechanisms, outline key concepts and results from the economic analysis of auctions, and summarize the key findings in empirical tests of auction theory. We then identify areas for future research on auction markets, particularly those of interest to marketers in the new contexts created by the Internet.
\end{abstract}

Key words: auctions, bidding behaviour, e-markets, experimental economics, economic psychology

Traditional auctioneers recognize the importance of marketing in their trade and discuss advertising principles and "the psychology of selling" as keys to auctioneering success. The growing popularity of Internet auctions is also driving new product-market and pricing models, revised channel roles, and new market research methods (Business Week 2001; Herschlag and Zwick 2000). Yet, the marketing literature on auctions is quite sparse. Despite suggestions (Rothkopf 1991) that auctions are a fertile area of study for marketing scientists, only a few theoretical and empirical papers (e.g., Sinha and Greenleaf 2000; Hoffman et al. 1993) address the topic. The anomaly has prompted calls for more research on auctions in marketing (Bazerman 2001; McAfee and McMillan 1996). This paper focuses attention on selected aspects of the research opportunity. We set the stage with a brief description of the four major auction mechanisms, outline key concepts and results from the economic analysis of auctions, and summarize the key findings in empirical tests of auction theory. We then identify areas for future research on auction markets, particularly those of interest to marketers in the new contexts created by the Internet. ${ }^{1}$

\title{
1. Auction Theory
}

Four basic auction mechanisms (ascending-bid, descending-bid, first-price sealed bid and second-price sealed bid) are commonly discussed in the literature. We briefly describe each mechanism, assuming that a single object is for sale and that a seller and several bidders operate without agents (Klemperer 1999).

\subsection{Auction Mechanisms}

In ascending-bid auctions, the object's price is raised until only a single bidder remains. This winning bidder pays a price equal to her last bid (usually a small amount more than the second highest bid). The auction is "open," i.e., the participants know the best current bid. In the "English" variant, a participant may hold back or enter bids at any time until a winner emerges (i.e., bidder exit information is not public). In the so-called "Japanese" variant, the price is increased continuously and bidders remain active until they exit publicly and irrevocably. Although rare in practice, many theoretical analyses assume the Japanese variant, in which the observed bids and exits provide information on the number 
of bidders, their willingness to bid, and their underlying values. An ascending auction is also called an open second-price auction.

In descending-bid ("Dutch") auctions, the auctioneer starts with a high initial price and progressively lowers it. The prevailing price is posted and known to all participants. The first bidder to indicate a willingness to take the object at the prevailing price is the winner. Because winners in open descending auctions pay their bid price, the Dutch auction is also called an open first-price auction. In contrast to open auctions, participants in sealed bid auctions submit their bids without seeing others' bids. In a first-price sealed bid (FPSB) auction, the highest bidder wins and pays his/her bid price. In a second-price sealed bid (SPSB) auction, the highest bidder also wins, but pays a price equal to the second highest bid. This mechanism is called a "Vickrey auction" after Vickrey (1961) who first explored its properties.

\subsection{Baseline Theoretical Analyses}

Auction mechanisms are usually analyzed as non-cooperative, incomplete (both symmetric and asymmetric) information games among competing bidders. The solution concept is the Bayesian Nash equilibrium in which bidders maximize their own expected payoffs from this single auction conditional on their rivals' strategies and their beliefs about the rivals' information (McAfee and McMillan 1987). The baseline analysis assumes single object auctions and a set of $n$ symmetric and risk neutral bidders.

Information Sets. Auction models differ in their assumptions about the bidders' information sets. In private value models, each bidder is assumed to know his/her own valuation of the object, but not others' valuations. In the baseline case, the valuations are assumed to be independent draws from a commonly known continuous distribution. Bidders' valuations vary, but are assumed to be unaffected by others' valuations. In contrast, with common value models, the object has the same "common" or "true" value for all bidders. However, bidders vary in their private "signals" (estimates) of the "common" value, with the signals assumed to be independent draws from the same continuous distribution. Bidders are uncertain of the object's worth and are influenced by information about others' signals revealed during the auction.

Milgrom and Weber (1982) formulated a general model in which each bidder has a private signal of the object's value. Other value measures (e.g., third party appraisals, etc.) may also be accessible to sellers (but not to bidders). Bidder values are symmetric functions of their own signals, others' signals, and the other value measures. The private signals and additional value measures are affiliated, i.e., their joint density functions reflect an information environment in which a higher value of some variables makes higher values of the other variables more likely. ${ }^{2}$ The independent private values (IPV) model is a special case in which bidders' signals are independent, and no additional value measures exist. The common value $(\mathrm{CV})$ model is a contrasting case in which there is a single additional value measure with all bidders' valuations equal to it. 
Bidding Strategies. In both descending and FPSB auctions, the bidder with the highest bid wins and pays the bid price. Hence, the bidding strategies and the mapping from strategies to outcomes for the two auction mechanisms are identical and they share the same (Nash) equilibrium. The equivalence holds as long as each bidder chooses her best bid given an assessment (correct in equilibrium) of other bidders' strategies. This strategic equivalence of the descending and first-price sealed bid auctions is a general result for single unit auctions. It holds whether or not buyers know their values and whether they are risk neutral or risk averse.

With IPVs, it is a dominant strategy for a bidder in an ascending auction to continue bidding until the price reaches her value. Eventually, the highest-value bidder wins, paying a price equal to the second-highest bid or a small amount more. In an SPSB auction, it is optimal for a bidder who knows her own value to submit a sealed bid equal to that value. At the dominant strategy equilibrium, the highest-value bidder wins at a price equal to the bid of the second-highest-value bidder. Thus, ascending and the SPSB auctions are equivalent if bidders know their private values. ${ }^{3}$

In $\mathrm{CV}$ auctions, the bidders independently estimate the object's value. If all bidders use the same monotonic strategy, and they all have unbiased estimates of value, then the high bidder has the highest of the unbiased estimates. However, the highest of the unbiased estimates is biased upwards. If bidders do not allow for this "order statistic property" in choosing their bids then (on average) the object will be worth less than the winning bid. This bad news implicit in winning is labeled the "winner's curse" (Capen et al. 1971). It is assumed that rational bidders can avoid the winner's curse (in equilibrium) by adjusting their bids downwards. Theoretically, this adjustment is costless since a bidder pays nothing if she loses.

Revenue Equivalence Theorem. Vickrey (1961) provided the earliest conceptualization and results on the equivalence (at equilibrium) of the expected revenues of various auction mechanisms. A contemporary statement of the Revenue Equivalence (RE) theorem (Klemperer 1999) is:

Assume $n$ symmetric risk neutral potential buyers of an object, each with a private signal $\left(t_{1}, \ldots, t_{n}\right)$ drawn independently from a common distribution $F(t)$ that is strictly increasing and atomless on $\left[t_{\ell}, t_{h}\right]$. Then, as long as (1) the object always goes to the buyer with the highest signal $t_{(1)}$, and (2) the buyer with the lowest feasible signal $\left(t_{\ell}\right)$ expects zero surplus, any auction mechanism yields the same expected revenue, and each bidder makes the same expected payment as a function of his/her signal.

The theorem implies that with risk-neutral bidders and independent signals, the expected revenue from any auction mechanism equals the winning bidder's expected marginal revenue (Bulow and Klemperer 1998). Also, from the seller's perspective, any of the auction mechanisms is optimal (revenue maximizing) as long as the RE conditions are supplemented by an optimal reserve price, below which no sale occurs. 


\subsection{Theoretical Extensions}

Affiliated Signals. Milgrom and Weber (1982) show that the RE results do not hold across all auction mechanisms if bidders' signals are affiliated. In (Japanese) open ascending auctions, bidding and exit behaviors are public and partially reveal the bidders' signals. With affiliation, this information should lead to higher prices relative to SPSB auctions where the signals are not revealed. In FPSB auctions, the winning bidder's expected payment is equal to her bid and does not depend on her valuation. However, in SPSB auctions, the winning bidder's expected payment depends not only on her bid, but also on her valuation (since the distribution of the remaining bids depends on her valuation). Thus, the bidder's expected payment rises with her own value since payment depends on estimates of competitors' values that are affiliated with her own (Milgrom 1989). Hence, the expected payment (and revenues) in SPSB auctions should be higher than in FPSB auctions. In summary, if bidder signals are affiliated, expected revenues are highest for open ascending auctions. SPSB auctions rank next, and are followed by FPSB auctions. The strategic equivalence of FPSB and open descending auctions holds generally for single objects (even if bidders do not know their private values). Table 1 (adapted from Klemperer 1999) compares bid strategies and winner payments (expected seller revenue) for various auction mechanisms with value/signal sets drawn from a uniform distribution. ${ }^{4}$

Risk Aversion. Consider first a risk-averse seller facing risk neutral buyers. With IPV, analyses of the expected prices and associated variances (Vickrey 1961) show that the riskaverse seller should be indifferent between the FPSB and descending auctions, and between SPSB and ascending auctions, with the former pair preferred to the latter. Other results (Waehrer et al. 1998) show an FPSB auction with an appropriate reserve price should be preferred to other mechanisms. In first- and second-price auctions, the more risk-averse a seller, the lower the optimal reserve price. Also, given two first-price auctions with reserve prices and entry fees implying the same screening level, risk-averse sellers prefer the auction with the lower entry fee.

These IPV results differ when risk-averse bidders face a risk-neutral seller. If a bid level in an FPSB auction is optimal for risk-neutral bidders, risk-averse bidders should bid more aggressively, since losing bidders get nothing and a higher bid raises the probability of winning (even if with a lower surplus). However, in SPSB (open ascending) auctions, it remains a dominant strategy for bidders to bid their values (continue bidding until the bid price exceeds their values). Thus, with a risk-neutral seller and risk-averse buyers, expected revenues are higher for FPSB and open descending auctions than for SPSB and open ascending auctions. However (see McAfee and McMillan 1987) the first-price auction may not be optimal for risk-neutral sellers who may wish to trade on risk and raise revenues by penalizing (subsidizing) low (high) bidders.

Information Asymmetries. Bidders lacking private information (or whose signal is known to another bidder) have no expected surplus at equilibrium in first- or secondprice auctions (Milgrom and Weber 1982). However, a bidder with even a small asymmetric information advantage over all competing bidders who otherwise have the 


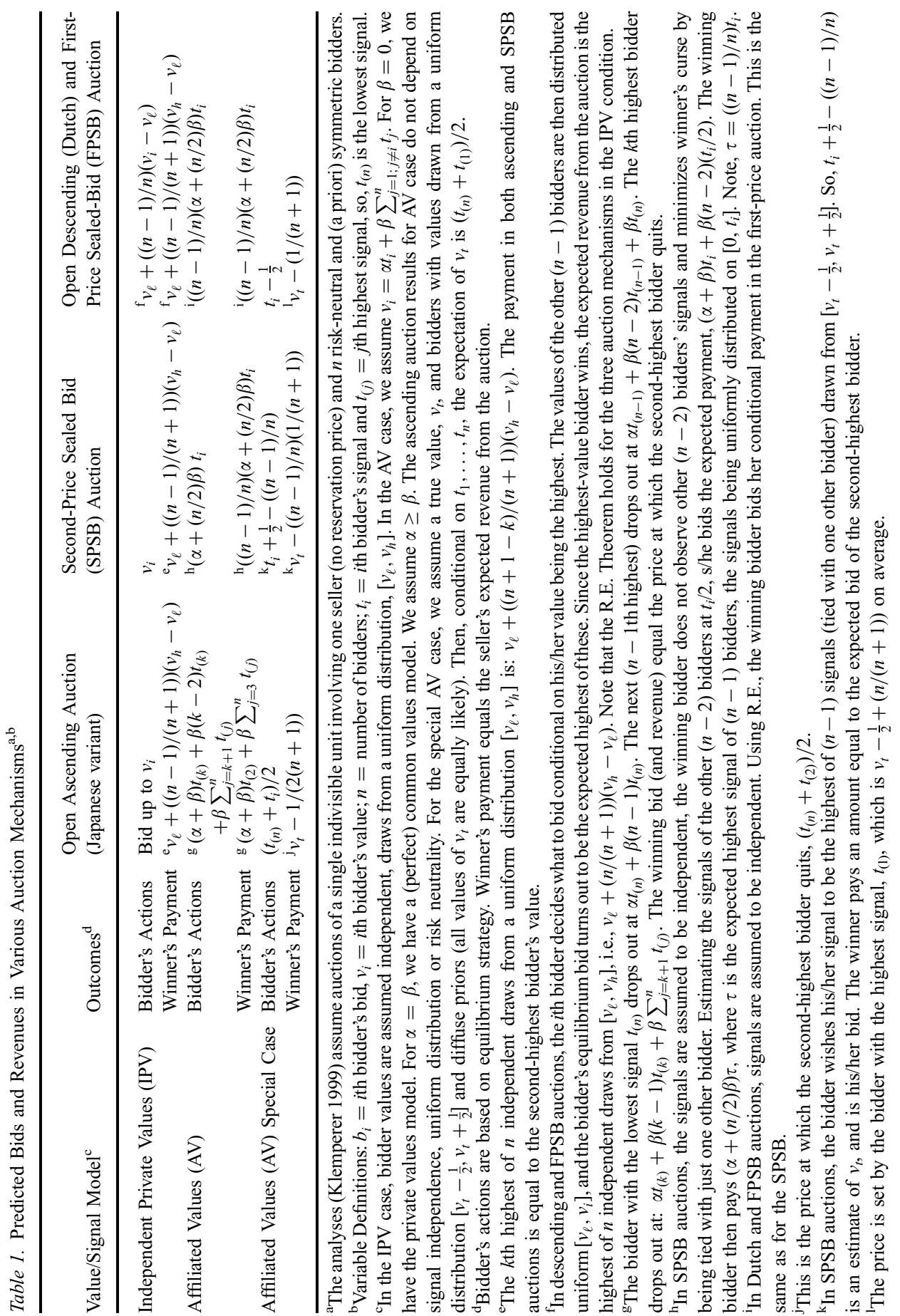


same common signal ("almost common values") enjoys a large strategic advantage in open ascending auctions, particularly in those without entry costs (Bikhchandani 1988). In first-price auctions, the symmetric equilibrium is less sensitive to small changes in information structure (Klemperer 1998). Also, bidder signals in the baseline case come from a common distribution, and revenue-maximizing auctions allocate objects to the bidder with the highest marginal revenue (versus highest value). But if bidder signals come from different distributions (i.e., different underlying demand schedules or marginal revenue functions) a first-price auction maximizes revenue but allocates less efficiently than a second-price auction (Maskin and Riley 1985).

Number of Bidders. In the baseline (IPV) case, RE holds whether or not the bidders know the number of buyers $(n)$ before bidding. However, RE does not imply identical price outcomes. In open ascending and SPSB auctions, the price exactly equals the secondhighest valuation. However, prices are generally unequal in the open descending and FPSB auctions. The dominant strategy for bidders in SPSB auctions (open ascending auctions) is to bid their value (remain in the auction until the bid price exceeds their value). However (Table 1) bidders in the open descending and the FPSB auctions will generally bid lower than their value, with the extent depending on $n$. Prices increase (on average) with $n$ as competition drives bids up, approaching the highest value in both first- and second-price auctions for large $n$ (McAfee and McMillan 1987).

\section{Empirical Tests of Auction Theory}

\subsection{Tests with Field Data}

One stream of empirical tests of auction theory focuses on estimating the underlying probability distribution of bidder valuations assuming Bayesian-Nash equilibrium strategies. The tests use cross-sectional bid data (e.g., for drainage lease auctions). Hendricks and Paarsch (1995) discuss a "structural approach" to estimating bid distributions for various auction mechanisms. The bid distribution is specified and estimated either in parametric form using maximum likelihood or non-linear least squares, or using nonparametric methods without explicit distributional assumptions (given data on all bids). The approach is tractable if IPVs are assumed, but identification is difficult for the range of distributions in the CV paradigm (Laffont 1997).

\subsection{Laboratory Experimental Tests}

A second research stream tests behavioral predictions of auction theory using laboratory experiments. The approach examines whether, given a set of buyer valuations and the underlying distribution of valuations, the bids and auction outcomes correspond to Bayesian Nash equilibrium strategies (see Kagel 1995). 
IPV Model Tests. Laboratory tests of the IPV model with symmetric bidders attempt to mimic model assumptions carefully. Subjects bid for one unit of a "fictitious commodity" (to avoid real world referents for which values may be affiliated) given independent values drawn from a uniform distribution (Table 1). Auction conditions are randomized to ensure the independence of valuations over trials.

RE typically fails in these tests. Subjects do not show strategically equivalent behaviors in the open descending and FPSB auctions (e.g., Cox et al. 1982, 1988) with prices typically higher in the latter. One proffered explanation (not empirically supported) is that the utility of the suspense of waiting in a descending auction is additive to that derived from auction income. A more likely explanation is that when no bids are offered as the clock ticks down, subjects lower estimates of rivals' valuations and underestimate their probability of being outbid. More research is needed to explain these observed failures of strategic equivalence.

The open ascending and the SPSB auctions also fail tests of strategic equivalence, with the latter yielding higher prices. Findings (e.g., Kagel and Levin 1993) suggest that these failures are not due to affiliated values or subject inexperience. Bids above the dominant strategy are common in second price auctions and are attributed to the opaque rationale for the dominant strategy (Note 3) and the fact that feedback is usually weak when subjects overbid by modest amounts. In ascending auctions, other bidders' actions are observable, and the impact of an above-value bid is relatively more transparent.

Studies (e.g., Cox et al. 1982, 1988; Dyer et al. 1989) manipulating the number of bidders $(n)$ find that bidding is above the risk neutral Nash equilibrium (RNNE). Increasing $n$ produces more aggressive bidding in first- but not in second-price auctions. Consistent with a normative analysis, Kagel and Levin (1993) find that increasing $n$ produces more aggressive bids in first-price auctions, no effects in second-price auctions, and less aggressive bids in third-price auctions. Also, consistent with constant or decreasing risk aversion, concealing information on $n$ raises average bids in first-price auctions (Dyer et al. 1989).

CV Model Tests. Experimental tests of the CV model focus mainly on the winner's curse. A common value $v_{t}$ is chosen from a uniform distribution on $\left[v_{\ell}, v_{h}\right]$. Each bidder then receives a private signal from a uniform distribution on $\left[v_{t}-\varepsilon, v_{t}+\varepsilon\right]$ with $\varepsilon$ commonly known. Although the signals are independent with respect to $v_{t}$, they are affiliated relative to the set of all possible signals. The winner (in first-price auctions) earns $v_{t}-b$ (where $b$ is the high bid) and losing bidders earn nothing. Subjects start with a cash balance, are allowed some practice trials, and receive feedback after each auction period. The number of bidders is fixed in most studies (e.g., Kagel and Levin 1986) and is endogenously determined by opportunity costs in one case (Cox et al. 2001).

The gap between the winning bid and the winner's expected value conditional on winning (i.e., having the highest signal) measures the extent of the winner's curse (Cox and Isaac 1984). For FPSB auctions, the curse is pervasive for inexperienced bidders (e.g., Kagel et al. 1986). With more experienced bidders, the extent declines but bid adjustments are less than complete. Subjects bid more aggressively when an exogenously fixed $n$ increases. When $n$ is endogenous, increases in the maximum possible number of bidders 
causes more exits, which reduces bidder aggressiveness (Cox et al. 2001). Replications (Kagel and Levin 1991; Lind and Plott 1991; Cox et al. 2001) confirm these results, eliminating explanations that subjects bid aggressively because their liability was limited to their starting cash balance.

Thus, in FPSB auctions, the winner's curse exists but is attenuated with experienced bidders. The attenuation stems from both bidder exits and learning-driven bid adjustments (Cox et al. 2001). With SPSB auctions, Kagel et al. (1994) report several breakdowns in RNNE theory. Also, contrary to the prediction that SPSB bids should be less aggressive with higher $n$, bid strategies are unchanged. The data also show that inexperienced bidders are unable to avoid the winner's curse in open ascending auctions. Drop out prices are above corresponding signal values, and tend to raise the winning bid (Kagel 1995).

$\boldsymbol{A} \boldsymbol{V}$ Model Tests. Experiments with affiliated signals use procedures similar to those for the CV model (Kagel 1995). For SPSB auctions, bids consistently exceed private values, whereas results for open ascending auctions are consistent with RNNE predictions (after some learning). With FPSB auctions, the RNNE model fits the data better than other selected discounting models incorporating strategic responses to $\varepsilon$ and $n$. However, public revelation of $v_{t}$ raises revenue. The intuition is that revealing $v_{t}$ surprises bidders with lower signals, who then raise their bids in an effort to win. These aggressive bids put pressure on bidders with higher signals, raising prices and revenue. However, the increase is smaller and has greater variability (attributed to risk aversion and individual level bidding errors, respectively) relative to RNNE theory (Kagel et al. 1987).

Risk Aversion. The risk aversion explanation of bidding above RNNE predictions is controversial. Cox et al. (1988) show that a model assuming heterogeneous bidders with power function utility (constant relative risk aversion - CRRA) fits their FPSB auction data better than models with symmetric risk neutral or risk-averse bidders. Indeed, a logconcave utility model (that nests CRRA and, in turn, the RN model) accounts for nearly all the data (Cox and Oaxaca 1996). Others argue that aggressive bidding may stem from low expected costs of deviation from RNNE in some study settings (Kagel 1995). However, the phenomenon persists even with higher expected deviation costs (Smith and Walker 1993) and tests using loss functions of expected deviation costs imply the same conclusions as tests based on prices, bids and values (Cox and Oaxaca 1996). Some authors advocate using binary lotteries to control risk preferences in testing auction theory.

Asymmetric Information. Empirical tests of auction theory predictions under asymmetric information are rare. The escalating strategic advantage predicted in "almost common value" situations is unexplored. In tests involving extreme asymmetry (an "insider" bidder with certain knowledge of value) the outsiders consistently bid higher than the expected value conditional on winning. Their bids remain aggressive even with knowledge of an insider or an asymmetrically informed rival, and the winner's curse persists (Kagel 1995). 


\section{Emerging Research Issues}

The above provides a contemporary review of auction theory (Klemperer 1999, 2000) and its empirical tests using field and experimental data (Hendricks and Paarsch 1995; Kagel 1995). Institutional aspects of auctions are discussed in both classic (e.g., Cassady 1967) and contemporary (e.g., Rothkopf 2001; Rothkopf and Harstad 1994) reviews. We now outline a selective agenda for auction research in marketing.

\subsection{Sociology of Auctions}

A forward-looking auctions research agenda for marketers may need grounding in ethnographic accounts of real-world auctions. C. Smith (1989) provides such a sociocultural analysis, arguing that auctions reveal less about "how competitive individual preferences are resolved through self-interested market behavior" but more about the "consensual and even cooperative character of most economic exchange." He notes that auction contexts are often emotion-laden and suggests that the outcomes reflect "communal legitimization of both price and allocation" given uncertainty about value, preferences and fairness. Collusion, signaling and other strategies are part of the "collective and consensual" exchange processes that auctions enable. This view of the individual and social nature of value determination processes is fertile for additional research.

\subsection{Construction of Value}

Evidence on labile and constructed values suggests that bidders may not enter auctions with fixed and immutable values (as in the IPV model). RE failures have been linked to the differential salience of price versus accept/reject judgments between open and sealed auctions. Similarly, failure to bid values in SPSB (but not in open ascending) auctions may stem from contextual variation in the transparency of the dominant strategy rationale (Kagel 1995). However, these assessments are speculative, as existing studies do not embed manipulations or measures that tease apart contextual effects on problem perception, value construction or value expression given the auctions' features. Moreover, in extant studies, subjects know their private valuations and the common distributional characteristics before participating in the auctions. Auction experiments in which subjects do not start with knowledge of their own value and/or the value distribution may show how value is constructed over repeated trials (e.g., Ariely et al. 2002). A methodological consideration here is the use of random- versus fixed-matching designs to control for reputation and other carryover effects.

For marketers, the $\mathrm{AV}$ model is an interesting context for examining value construction in auctions. The literature (e.g., Klemperer 1999; Milgrom and Weber 1982) provides intuitive examples of IPV, CV and AV situations using specific combinations of objects and bidder motivations. For example, an antique or a painting purchased by a consumer for personal use versus by a dealer for resale contrast IPV and CV situations. The AV situation 
incorporates features of each scenario where bidder values depend not only on their own signals but also on those of others. However, there is little taxonomic guidance for buyers/ sellers on how values may be correlated for real goods and services and influence auction outcomes. It is also unclear how the AV model handles cases where consumer subgroups have negatively and/or asymmetrically correlated values.

Experimenters (e.g., Kagel 1995) have used elegant procedures to create private values satisfying a technical definition of affiliation (Milgrom and Weber 1982). However, these "fictitious commodity" studies leave questions about subjects' behavior when they culturally share affinity for common objects, take cues from bids and exit behaviors in open auctions, or emulate others based on perceived expertise or social distance. Experiments in richer environments with real objects (scaled for hedonic or functional properties) and studies manipulating bidding and exit maneuvers and emulation imperatives (e.g., bidders imbued with product and process expertise, or scaled for social distance) may illuminate value construction processes in various auction mechanisms. The methodology must account for sequential dependencies and the effects of wins and losses that drive rates and patterns of adaptive learning. Design and measurements must discriminate learning processes that truly alter value from "informational cascades," (Bikhchandani et al. 1992), where affiliation induces strategic emulation of preceding bidders without consideration of one's private signal.

\subsection{Bidding Strategy}

The winner's curse continues to generate debate (e.g., Cox and Isaac 1984; Cox et al. 1999; Campbell et al. 1999). The evidence suggests that endogenous entry and moderate experience reduce the winner's curse in fictitious commodity auctions (Cox et al. 2001). Yet, as in the AV experiments, the studies do not address whether learning is at the market level or whether individual bidders learn to exorcise the winner's curse by normatively adjusting their bids. Bazerman (2001) suggests that consumers maintain a belief that they receive good values in auctions. Whether or not they experience the regret they should upon bidding aggressively and winning may depend on their cognitive skills for counterfactual reasoning (Tsiros and Mittal 2000) and their facility with motivational processes (e.g., dissonance and attribution) for managing the emotions of victory and defeat. A relevant issue is whether sellers in CV auctions experience the reciprocal joy implied by the winner's curse. Finally, recent research (Cox and Hayne 2001) examines the winner's curse in $\mathrm{CV}$ situations where committees prepare bids, and also compares committees and individuals on their rational use of information.

\subsection{Internet Auctions}

Internet auctions appeal widely to consumers and collectors (Business Week 2001) and are providing new field results for academics (Ariely and Simonson 2002; Häubl and Popkowski-Leszczyc 2001). Auctioning collectible trading cards over the Internet, 
Lucking-Reiley (1999) found that open descending auctions produce significantly higher revenues than FPSB auctions. The data violate RE, but in a direction opposite to those in all prior lab studies. Research is needed on whether the results are attributable to differences in the number of bidders attracted and/or to constructed (or affiliated) values for the real goods in the Internet auctions (versus fictitious commodities used in lab studies). Also, slower clock speeds may elicit higher bids due to either bidder impatience or unwillingness to bear the transaction costs of returning to the auction later.

These and other findings suggest substantive contrasts between the brick and mortar (BM) and Internet auction houses. One set of contrasts lies in the nature of the two bidder communities and the social context. Most BM auctions are synchronous and provide some access to bidder identity and to verbal/nonverbal communication cues. In contrast, the explicit social context in Internet auctions is relatively impoverished, notwithstanding individual and product category differences. Other differences relate to product authentication and warranties. BM auction houses offer verifiability through explicit or implicit quality indemnities as well as buyer/seller information (subject to some buyers' use of agents). With Internet auctions providing more extensive transaction histories and buyer/ seller ratings, changing perceptions of informational advantages (and of product standardization) may influence bidding. These issues influence the flexibility that Internet auctions offer sellers on choosing modes and cost levels for their bidder attraction efforts (Sinha and Greenleaf 2001).

Products not sold the first time that they are offered at an auction suffer implicit "damage" that lowers value in subsequent sale efforts. In Internet auctions, this devaluation of listed but unsold products appears to be less drastic than in BM auctions. Along with lower listing costs and commissions, this may prompt sellers to take more risk on-line with higher reserves. Also, BM and Internet auctions operate on different timelines with regard to the auction clock and outcome announcements. Longer waits and slower clocks in Internet auctions may create differences that influence bidder behavior. "Sniping," (where new bidders enter in the closing minutes of an Internet auction) introduces strategic and structural uncertainties that may influence perceptions of procedural fairness, and affect preferences for auction formats. Although efforts are sometimes made to control sniping through ad hoc rules and technology constraints, there is little formal analysis of their effects on bidder preferences and participation. Consideration of seller preferences (e.g., by firm and product characteristics) may suggest alternative formats that may better match buyers and sellers in both BM and Internet environments.

\subsection{Alternative Auction Formats}

The Internet raises new questions about the design of alternative auction formats to impose regularity and discipline on the behavior of market participants. One issue is how the winning bidders are identified. Although traditional auctions sell to the highest bidder, an alternative is to use probabilistic rules to determine winners. ${ }^{5}$ Also, in multi-stage auctions, the sequence of mechanisms and information revelation across stages should influence bidder strategies, fairness perceptions and allocation efficiency. Hence, judicious sequen- 
cing may show how values and bidding strategies evolve. Another issue is how Internet auctions end. The finish time may be random (drawn from a commonly known distribution), or involve "soft" (e.g., Amazon.com) or "hard" (e.g., eBay) ends. Even as mechanisms change with buyer/seller experimentation, research is needed on how such institutional features influence bidding behavior and price/revenue outcomes (Roth and Ockenfels 2002).

Auctions can accommodate marketing practices such as bundling multiple items with complementary value. Research on multiunit auctions is sparse and there is room for theoretical analysis (e.g., Palfrey 1983) or for building grounded theory via laboratory or field experiments. Rothkopf (2002) notes the possibility of better expression of the value synergies associated with a group of assets through combinatorial auctions that allow bidders to submit bids for self-selected combinations.

More research is needed on price formation processes in double auction markets where buyers and sellers are treated symmetrically in terms of submitting bids and asks (e.g., Friedman and Rust 1993). The goals driving the choice of matching and allocation procedures in these markets may vary. For example, the matching market trading institution which progressively matches the highest bids and the highest asks should maximize transaction volume. However, tests (Rich and Friedman 1998) show that such institutions may generate variable trading volume and compromise efficiency relative to the standard uniform price trading institution.

Effective market mechanisms should facilitate truthful revelation of values, encourage relevant player participation, and resist invasion by alternative institutions. Recent successes and failures in cyberspace markets (e.g., eBay and Priceline.com respectively) raise new institutional issues (Friedman et al. 2001). Should sniping be discouraged via institutional rules or permitted with transaction fees linked to elapsed time? Should access to order flow information be restricted and how should access rules and fees be structured? Should automated buyers and sellers be encouraged? New theories, backed by simulations of trade and market interactions, are needed to identify factors that hinder or make exchange costly in cyberspace markets, and to suggest how institutional structure (including intermediary functions) may mitigate these obstacles. Evidently, initial predictions of widespread "disintermediation" in cyberspace markets were based on simplistic premises.

\section{Conclusion}

Marketers face rich opportunities for theoretical, empirical and experimental research on buyer and seller behavior in auctions. This paper has selectively reviewed the economic theory of auctions and provided a synopsis of the key findings of empirical tests. We have identified several future research questions, including those arising in the new market contexts created by the Internet. We hope that the discussion stimulates additional work that enriches our understanding of firm and consumer behavior in the emerging marketplace. 


\section{Notes}

1. Due to space constraints, this version of the paper is significantly abridged and contains a selected reference list that focuses on more recent papers. An unabridged version (Chakravarti et al. 2002) which contains additional discussion and a complete list of references is available from the first author.

2. Two signals $t_{1}$ and $t_{2}$ are affiliated if for all $t_{1}^{\prime}>t_{1}^{\prime \prime}$ and $t_{2}^{\prime}>t_{2}^{\prime \prime}$ (where $t_{i}^{\prime}$ and $t_{i}^{\prime \prime}$ are different realizations of $t_{i}$ and $f\left(t_{1}, t_{2}\right)$ is the joint density function of the signals), we satisfy the relationship $\left[f\left(t_{1}^{\prime}, t_{2}^{\prime}\right)\right.$. $\left.f\left(t_{1}^{\prime \prime}, t_{2}^{\prime \prime}\right)\right] \geq\left[f\left(t_{1}^{\prime}, t_{2}^{\prime \prime}\right) \cdot f\left(t_{1}^{\prime \prime}, t_{2}^{\prime}\right)\right]$. Applying the conditional probability law (i.e., $f\left(t_{1}, t_{2}\right)=\left[g\left(t_{1} \mid t_{2}\right) \cdot h\left(t_{2}\right)\right]$, where $g\left(t_{1} \mid t_{2}\right)$ is the conditional density of $t_{1}$ given $t_{2}$, and $h\left(t_{2}\right)$ is the marginal density of $t_{2}$ ) this translates to the Monotone Likelihood Ratio Property $\left[g\left(t_{1}^{\prime} \mid t_{2}^{\prime}\right) / g\left(t_{1}^{\prime \prime} \mid t_{2}^{\prime}\right)\right] \geq\left[g\left(t_{1}^{\prime} \mid t_{2}^{\prime \prime}\right) / g\left(t_{1}^{\prime \prime} \mid t_{2}^{\prime \prime}\right)\right]$. With independent signals, this affiliation condition holds weakly (i.e., as an equality). Affiliation has a stronger implication than the simple existence of a global correlation between the signals and requires local positive correlation everywhere in the domain of the signals (see Klemperer 1999; Milgrom and Weber 1982).

3. Consider a bidder with value $v$ in a second price auction where $w$ is the highest other bid. Assume that the bidder submits a "shaded" bid, $v-x$. If $v-x>w, \mathrm{~s} /$ he wins and pays $w$ just as $\mathrm{s} /$ he would have if $\mathrm{s} / \mathrm{he}$ bid $v$. Also, if $w>v, \mathrm{~s} / \mathrm{he}$ loses and pays nothing just as if s/he bid $v$. But, if $v>w>v-x$, the bidder loses the auction by bidding $v-x$ and forfeits the surplus $v-w$ obtained by bidding $v$ and winning. Thus the bidder never gains by submitting a shaded bid, but may lose some surplus. Now assume that the bidder submits an aggressive bid $v+x$. If $v>w$, the bidder wins and pays $w$ just as if $\mathrm{s} / \mathrm{he}$ bid $v$. If $w>v+x$, the bidder loses and pays nothing just as s/he would have by bidding $v$. However, if $v+x>w>v$, then the bidder wins but pays an amount $w>v$ and has a negative surplus. Thus, the bidder never gains by submitting an aggressive bid that exceeds value, but may have a negative surplus. Hence, it is dominant for the bidder to submit a bid equal to his/her value (see also Klemperer 1999).

4. For the IPV case, the predicted bids and revenues are identical for the Japanese and English variants of the open ascending auction. Therefore RE holds irrespective of the specific variant considered.

5. Given an ordered set of bids, $b_{1}, b_{2}, \ldots, b_{n}$, the probability that bidder $i$ wins is: $P(i)=$ $b_{i}^{c} / \Sigma b_{j}^{c} ;\left(b_{j} \geq 1 ; c \geq 1\right)$. Thus, the higher the bid, the higher is the probability of winning the auction. Equal bids have equal win probabilities. The rule reduces to the traditional deterministic rule when $c \rightarrow \infty$.

\section{References}

Ariely, Dan, and Itamar Simonson. (2002). "Buying, Bidding, Playing or Competing? Value Assessment and Decision Dynamics in Online Auctions," Journal of Consumer Psychology, forthcoming.

Ariely, Dan, George Loewenstein, and Drazen Prelec. (2002). "Coherent Arbitrariness: Stable Demand Curves Without Stable Preferences," Working Paper, Sloan School of Management, MIT, Cambridge, MA.

Bazerman, Max. (2001). "Consumer Research for Consumers," Journal of Consumer Research, 27(4), 499-504.

Bikhchandani, Sushil, David Hirshleifer, and Ivo Welch. (1992). "A Theory of Fads, Fashion, Custom and

Cultural Change as Informational Cascades," Journal of Political Economy, 100(5), 992-1026.

Business Week e.biz. (2001). "eBay: The People's Company," December 3, EB15-EB21.

Campbell, Colin M., John H. Kagel, and Dan Levin. (1999). "The Winner's Curse and Public Information in Common Value Auctions: Reply,” American Economic Review, 89(1), 319-334.

Capen, Edward, Robert Clapp, and William Campbell. (1971). "Competitive Bidding in High Risk Situations," Journal of Petroleum Technology, 23, 641-653.

Cassady, Ralph, Jr. (1967). Auctions and Auctioneering, Berkeley, CA: University of California Press.

Chakravarti, Dipankar, E. Greenleaf, A. Sinha, A. Cheema, J. Cox, D. Friedman, T. Ho, M. Isaac, A. Mitchell, A. Rapoport, M. Rothkopf, J. Srivastava, and R. Zwick. (2002). “Auctions: Research Opportunities in Marketing," Working Paper, University of Colorado, Boulder, CO.

Cox, James, Bruce Roberson, and Vernon L. Smith. (1982). "Theory and Behavior of Single Object Auctions.” In V. L. Smith (ed.), Reseach in Experimental Economics. Greenwich, CT: JAI Press, 1-43. 
Cox, James, and Ronald Oaxaca. (1996). "Is Bidding Behavior Consistent with Bidding Theory for Private Value Auctions?" In M. Isaac (ed.), Research in Experimental Economics, Greenwich, CT: JAI Press, 131-148.

Cox, James C., Samuel Dinkin, and Vernon L. Smith. (1999). "The Winner's Curse and Public Information in Common Value Auctions: Comment," American Economic Review, 89(1), 319-324.

Cox, James C., Samuel Dinkin, and James T. Swarthout. (2001). "Endogenous Entry and Exit in Common Value Auctions," Experimental Economics, 4, 163-181.

Cox, James C., and Stephen C. Hayne. (2001). "Group Versus Individual Decision Making in Strategic Market Games," Working Paper, University of Arizona, Tucson, AZ 85721.

Friedman, Daniel, and J. A. Rust (eds.). (1993). The Double Auction Market: Institutions, Theory and Evidence. Redwood City, CA: Addison-Wesley.

Friedman, Daniel, Bernardo Huberman, and Nirvikar Singh. (2001). "Cyberspace Market Institutions," Presentation at the 2001 UC Berkeley, Choice Symposium, June.

Hendricks, Kenneth, and Harry J. Paarsch. (1995). "A Survey of Recent Empirical Work Concerning Auctions," Canadian Journal of Economics, 28(2) (May), 403-426.

Herschlag, Miriam, and Rami Zwick. (2000). "Internet Auctions-A Popular and Professional Literature Review," Quarterly Journal of e-Commerce, 1(2), 161-186.

Hoffman, Elizabeth, Dale J. Menkhaus, Dipankar Chakravarti, Ray A. Field, Glen D. Whipple. (1993). "Using Laboratory Experimental Auctions in Marketing Research: A Case Study of New Packaging for Fresh Beef," Marketing Science, 12 (Summer), 318-338.

Kagel, John H. (1995). “Auctions: A Survey of Experimental Research.” In John H. Kagel and Alvin E. Roth (eds.), 7, The Handbook of Experimental Economics. Princeton, NJ: Princeton University Press, 501-585.

Kagel, John H., and Dan Levin. (1993). "Independent Private Value Auctions: Bidder Behavior in First-, Secondand Third-Price Auctions with Varying Numbers of Bidders," Economic Journal, 103, 868-879.

Klemperer, Paul. (1999). “Auction Theory: A Guide to the Literature," Journal of Economic Surveys, 13(3), 227260

Klemperer, Paul (ed.) (2000). “The Economic Theory of Auctions,” Volumes 1 \& 2, Cheltenham, UK: Edward Elgar.

Laffont, Jean-Jacques. (1997). "Game Theory and Empirical Economics: The Case of Auctions Data," European Economic Review, 41, 1-35.

Lucking-Reiley, David. (1999). "Using Field Experiments to Test Equivalence Between Auction Formats: Magic on the Internet," American Economic Review, 89(5), 1063-1080.

McAfee, R., Preston, and John McMillan. (1987). “Auctions and Bidding," Journal of Economic Literature, 25 (June), 699-738.

McAfee, R., Preston, and John McMillan. (1996). "Competition and Game Theory," Journal of Marketing Research, 25 (August), 263-267.

Milgrom, Paul, R., and Robert J. Weber. (1982). "A Theory of Auctions and Competitive Bidding," Econometrica, 50(5), 1089-1122.

Rich, Changhua, and Daniel Friedman. (1998). "The Matching Market Institution: A Laboratory Investigation," American Economic Review, 88(5) (December), 1311-1322.

Roth, Alvin E., and Axel Ockenfels. (2002). "Last-minute Bidding and the Rules for Ending Second Price Auctions: Theory and Evidence from a Natural Experiment on the Internet." American Economic Review (forthcoming).

Rothkopf, Michael. (2002). "Modeling Opportunities in Auction", in Brenda Dietrich and Rakesh Vohra (eds.), Mathematics of the Internet: E-Auctions and Markets, IMA volumes in Mathematics and its Applications, 127, New York, NY, Springer-Verlag.

Rothkopf, Michael, and Ronald M. Harstad. (1994). "Modeling Competitive Bidding: A Critical Essay," Management Science, 40(3), 364-384.

Sinha, Atanu, and Eric Greenleaf. (2000). "The Impact of Discrete Bidding and Bidder Aggressiveness on Sellers' Strategies in Open English Auctions: Reserves and Covert Shilling," Marketing Science, 19(3), 244265.

Smith, Charles, W. (1989). Auctions: The Social Construction of Value. New York, NY: The Free Press. 
Tsiros, Michael, and Vikas Mittal. (2000). "Regret: A Model of its Antecedents and Consequences in Consumer Decision Making," Journal of Consumer Research, 26(4), 401-417.

Waehrer, Keith, Ronald M., Harstad, and Michael H. Rothkopf. (1998). "Choice of Auction Type for Risk-Averse Bidtakers," Rand Journal of Economics, 29, 179-192. 